\title{
BMJ Global Health The legitimacy of modelling the impact of an intervention based on important intermediate outcomes in a trial
}

To cite: Cousens S, Head R. The legitimacy of modelling the impact of an intervention based on important intermediate outcomes in a trial. BMJ Glob Health 2018;3:e001222. doi:10.1136/ bmjgh-2018-001222

Handling editor Seye Abimbola

Received 12 0ctober 2018 Accepted 15 October 2018

\section{CSLinked}

- https://doi.org/10.1136/ bmjgh-2018-001194

- https://doi.org/10.1136/ bmjgh-2018-000808

Check for updates

(c) Author(s) (or their employer(s)) 2018. Re-use permitted under CC BY-NC. No commercial re-use. See rights and permissions. Published by BMJ.

${ }^{1}$ Centre for Maternal Adolescent Reproductive and Child Health (MARCH), London School of Hygiene and Tropical Medicine, London, UK

${ }^{2}$ Development Media

International, London, UK

Correspondence to

Roy Head;

roy@developmentmedia.net
Colbourn $e t$ al raise three interesting questions. (1) Whether, if a randomised controlled trial (RCT) fails to detect an effect on the primary outcome but shows a significant effect on an intermediate outcome, it is legitimate to model the effect? (2) Whether the modelling was performed correctly? and (3) Whether it is meaningful to focus on demand-side factors in isolation?

(1) We would argue that it is legitimate to use a model to evaluate an effect that the RCT was not, and could not be, powered to detect, where there is strong evidence of an impact on an important intermediate outcome, provided the limitations of such an exercise are appropriately acknowledged.

Measuring the effect of media campaigns is challenging. Very few countries have the very low national radio and television penetration and high local radio listenership that make it possible to evaluate a radio campaign through a cluster randomised trial. ${ }^{2}$ Even in those few countries where media configurations are suitable, the power to detect important changes in mortality is constrained by the mortality rate and the number of clusters that can be achieved (14 in the case of Burkina Faso).

When we began our study in 2011, we designed our trial to have $80 \%$ power to detect a mortality reduction of $20 \%$ but just $30 \%$ and $8 \%$ power to detect reductions of $10 \%$ and $5 \%$ respectively. Due to the constraints outlined above, it was impossible to power the study to detect small reductions. Rapidly falling mortality during the study period (from 115.5/1000 to 76.5/1000 in the control arm) will have further reduced our study's power. Given the lack of power to detect a reduction in mortality in the range of $5 \%-10 \%$, it is important to remember that 'absence of evidence is not evidence of absence'. Colbourn et al attach considerable importance to the point estimate, but our mortality estimates do not preclude anything from an important negative effect to an important positive effect.

\section{Summary box}

A cluster randomised controlled trial in Burkina Faso evaluating the impact of a mass media behaviour change campaign showed a highly significant impact on child consultations for malaria $(56 \%$ increase in 1st year), diarrhoea (73\%) and pneumonia (39\%), but did not detect an effect on child mortality.

- The trial was not, and could not be, adequately powered to detect a reduction in child mortality of $10 \%$ or less, so a well-established modelling tool was used to estimate the effect of these intermediate outcomes on lives saved.

- Modelling was considered justified in the context of strong improvement in these important intermediate outcomes and good availability of the drugs needed to treat malaria, diarrhoea and pneumonia.

- Demand-side interventions are not a substitute for health system strengthening or other supply-side interventions, but treatment seeking is a necessary precondition for any child to receive life-saving treatment.

More generally, it is also important not to overstate the certainty provided by survey-based methods which rely on mothers' recall to estimate child mortality trends in countries lacking fully functioning vital registration systems. Mortality surveys can be subject to uncertainties greater than the effect sizes we were attempting to measure.

We did observe important changes in behaviour, using health centre records of over 600000 consultations: a $56 \%$ increase in parents taking their children for malaria treatment $(p<0.001)$ in the first year and similar results for pneumonia $(39 \%, \mathrm{p}<0.001)$ and diarrhoea $(73 \%, \mathrm{p}<0.001){ }^{3}$ Given the survey's lack of power to detect smaller changes in mortality, we used LiST to estimate the effect of increased care seeking on mortality. LiST is a widely used and accepted tool for estimating the likely mortality impact of different interventions. The cost-effectiveness calculations simply follow from the mortality reductions predicted by 
LiST. The stated conclusion of our study was that 'large-scale mass media campaigns encouraging prompt care seeking for children can be highly cost-effective in improving child survival. ${ }^{4}$

(2) Colbourn et al raise four methodological concerns:

1. With regard to the 'compression' of the consultation counts, we adopted this approach in the context of multiple diagnoses during one consultation to avoid double-counting deaths averted. The method was applied consistently and correctly to all three diagnoses.

2. For pneumonia treatment rates, we used the LiST default approach which is to use the consultation rate with no adjustment for treatment rate. LiST takes this approach based on evidence that pneumonia treatment rates estimated from survey data are not valid. ${ }^{56}$ This has limited effect on the projections because the assumption applies to both the intervention and control groups (and because pneumonia represents a small percentage of the total lives saved). If we reduce the percentage of pneumonia cases treated from $52.7 \%$ to $44.8 \%$, corresponding to reduced treatment arising from amoxicillin and cotrimoxazole stockouts, ${ }^{7}$ the effect on the projected lives saved is small (from $7.1 \%$ to $6.9 \%$ ).

3. The reasons for the relative decrease in consultations for 'other diagnoses' in the trial's intervention arm are unclear; however, it is worth noting that 'other' diagnoses actually increase in both arms. This could possibly be due to strengthening in the implementation of Integrated Management of Childhood Illness. However, because the 'other' consultation data were aggregated, we lacked the data to investigate which diagnoses contributed to these trends.

4. Colbourn et al are correct that the lower bound of the reported lives saved for 2014, reported in table 1 in Murray $e t a l^{3}$ should be negative. The correct lower bounds for 2013 and 2014 should be 35 and -14, respectively, with the overall lower bound being 798 and not 1110. This error affects only the lower bounds and not the overall percentage reduction in mortality which remains at $7.1 \%$.

(3) While Colbourn et al are, of course, correct that health systems are complex and that treatment seeking is worthless without available treatments and a functioning health system, the reverse argument is also true: if sick children are not brought for treatment, no health system is going to be able to save their lives. Very few would argue that appropriate treatment with effective antimalarials, antibiotics and oral rehydration salt (ORS) cannot save lives, and WHO and UNICEF have recommended prompt care seeking for these conditions for many years. ${ }^{89}$ Care seeking is an important intermediate outcome and a precondition for everything that follows in the causal pathway leading to deaths averted. There are therefore strong grounds for believing that, if the health system is functioning reasonably well, improvements in care seeking can save lives.

In Burkina Faso, the evidence suggests that the health system was functioning reasonably well. As we note in the article, the WHO 2014 Service and Availability Readiness Assessment report indicates good availability of key lifesaving treatments in primary health facilities in Burkina Faso: $91 \%$ for malaria treatment, $82 \%$ for ORS sachets and $83 \%-85 \%$ for antibiotics. ${ }^{7}$

In conclusion, we consider that it is legitimate to use a well-established modelling tool to estimate a health impact when there is strong evidence of an impact on an important intermediate outcome but little or no power to detect an impact on the health outcome itself. The limitations of such an exercise, of course, must be appropriately acknowledged.

However, we are in complete agreement that demandside interventions are not a substitute for health systems strengthening or other supply-side interventions. Our study simply shows that demand-side interventions should not be confined to the periphery of public health and have the potential to save lives when used as part of a functioning health system.

Contributors SC and RH jointly drafted the letter.

Funding This study was funded by Planet Wheeler Foundation, Wellcome Trust (Grant 091367/Z/10/Z).

Competing interests None declared.

Patient consent Not required.

Ethics approval The ethics committees of the Ministry of Health of Burkina Faso and the London School of Hygiene and Tropical Medicine.

Provenance and peer review Commissioned; internally peer reviewed.

Data sharing statement No additional data are available.

Open access This is an open access article distributed in accordance with the Creative Commons Attribution Non Commercial (CC BY-NC 4.0) license, which permits others to distribute, remix, adapt, build upon this work non-commercially, and license their derivative works on different terms, provided the original work is properly cited, appropriate credit is given, any changes made indicated, and the use is non-commercial. See: http://creativecommons.org/licenses/by-nc/4.0

\section{REFERENCES}

1. Colbourn T, Prost A, Seward N. Making the world a simpler place: the modeller's temptation to seek alternative trial results. BMJ Glob Health 2018;3:e001194.

2. Head R, Murray J, Sarrassat S, et al. Can mass media interventions reduce child mortality? Lancet 2015;386:97-100.

3. Murray J, Head R, Sarrassat S, et al. Modelling the effect of a mass radio campaign on child mortality using facility utilisation data and the Lives Saved Tool (LiST): findings from a cluster randomised trial in Burkina Faso. BMJ Glob Health 2018;3:e000808.

4. Kasteng F, Murray J, Cousens S, et al. Cost-effectiveness and economies of scale of a mass radio campaign to promote household life-saving practices in Burkina Faso. BMJ Glob Health 2018;3:e000809.

5. Campbell H, El Arifeen S, Hazir T, et al. Measuring coverage in $\mathrm{MNCH}$ : challenges in monitoring the proportion of young children with pneumonia who receive antibiotic treatment. PLoS Med 2013;10:e1001421.

6. Hazir T, Begum K, El Arifeen S, et al. Measuring coverage in $\mathrm{MNCH}$ : a prospective validation study in Pakistan and Bangladesh on measuring correct treatment of childhood pneumonia. PLoS Med 2013;10:e1001422.

7. WHO, 2014. WHO Service and Availability Readiness Assessment (SARA) for Burkina Faso. Available from: http://www.who.int/healthinfo/ systems/sara_reports/en/

8. Geldsetzer P, Williams TC, Kirolos A, et al. The recognition of and care seeking behaviour for childhood illness in developing countries: a systematic review. PLoS One 2014;9:e93427.

9. WHO. The role of $\mathrm{IMCl}$ in improving family and community practices to support child health and development. Geneva: World Health Organization, 1999. 